\title{
Surviving meningococcal septic shock in childhood: long-term overall outcome and the effect on health-related quality of life
}

\author{
Corinne MP Buysse*1, Lindy CAC Vermunt 2 , Hein Raat ${ }^{3}$, Jan A Hazelzet ${ }^{1}$, Wim CJ Hop ${ }^{4}$, Elisabeth MWJ Utens² and \\ Koen FM Joosten ${ }^{1}$
}

\begin{abstract}
Introduction: The purpose of this study was to evaluate associations between long-term physical and psychological outcome variables in patients who survived meningococcal septic shock (MSS) in childhood.

Methods: The study population was made up of all MSS patients requiring intensive care treatment between 1988 and 2001.

Results: A total of 120 patients visited the follow-up clinic (age at paediatric intensive care unit (PICU) admission 3.1 years; follow-up interval 9.8 years; age at follow-up 14.5 years (all medians)). Four major outcomes were considered: 1) major physical sequelae (defined as major scars and/or orthopaedic sequelae) (29/120), 2) mild neurological impairments (39/120), 3) problem behaviour (defined as a total score above the $90^{\text {th }}$ percentile of the reference groups on questionnaires to screen for psychopathology) (16/114) and 4) total intelligence quotient < 85 (18/115). No differences were found between patients with major physical sequelae and patients without major physical sequelae as to the presence of problem behaviour or total $I Q<85$. Also, no differences were found between patients with mild neurological impairments and patients without as to the presence of problem behaviour or total IQ $<85$. Finally, no differences were found between patients with major physical sequelae and patients without as to the presence of mild neurological sequelae. Less favourable scores on behavioural and emotional problems were significantly associated with poorer health-related quality of life (HR-QoL). HR-QoL scores were to a lesser amount predicted by severity of illness at time of PICU admission or by adverse physical outcome.
\end{abstract}

Conclusions: Long-term adverse physical and psychological outcomes in survivors of MSS did not seem to be associated. Poorer HR-QoL was mainly predicted by problem behaviour.

\section{Introduction}

The research presented here is part of a medical and psychological follow-up study of all consecutive surviving patients with meningococcal septic shock (MSS) requiring intensive care treatment between 1988 and 2001 at the Erasmus MC-Sophia Children's Hospital, Rotterdam, The Netherlands. This follow-up study revealed that these patients suffered from mild to severe long-term skin scarring, orthopaedic sequelae and neurological impairments. These patients had significantly higher

\footnotetext{
* Correspondence: c.buysse@erasmusmc.nl

1 Department of Paediatrics, Division of Paediatric Intensive Care, Erasmus MCSophia Children's Hospital, Dr. Molewaterplein 60, Rotterdam, 3015 GJ, The Netherlands

Full list of author information is available at the end of the article
}

severity of illness scores than patients without sequelae. Furthermore, they were assigned significantly poorer HRQoL (health-related quality of life) scores, compared with normative data, though mainly on the physical domains. Overall, behavioural/emotional outcomes and cognitive functioning were normal [1-5].

Until now associations between different outcome variables in MSS survivors have not been investigated. We hypothesize that adverse outcome variables are clustered together, not independently distributed. So patients suffering from severe skin scarring or extensive amputation would also show more problem behaviour and cognitive dysfunctioning. Furthermore we hypothesize that they show poorer HR-QoL. 
The present study is by no means a replicate of data already published. Indeed there are points of similarity (the patient sample, outcome variables) among previously published papers in our present study. However, in the present study our primary aim was to evaluate associations between long-term outcome variables, both physical and psychological, in patients who survived MSS in childhood. This knowledge would enable us to identify risk for overall adverse long-term outcome. The secondary aim was to assess various putative determinants of adverse overall outcome and HR-QoL.

\section{Materials and methods Patient selection}

Patients were recruited from the PICU of the Erasmus MC-Sophia Children's Hospital, a tertiary care university hospital. Eligible for inclusion were all consecutive surviving patients aged 1 month to 18 years with a clinical picture of MSS, as well as their parents. Meningococcal septic shock was defined as septic shock with petechiae and/or purpura [6]. The Erasmus MC Medical Ethical Review Board approved the study protocol. Written informed consent was obtained from parents and patients after they had received a standard letter requesting their participation. Those with insufficient command of the Dutch language were excluded. Parents and patients who agreed to participate $(n=120)$ were invited by mail to arrange a visit to the follow-up clinic. The follow-up visits took place in 2005 and 2006.

\section{Data analysis at PICU admission}

During the study period patients consecutively admitted with MSS were included in several sepsis studies [7-11]. Severity of illness was determined by the Pediatric Risk of Mortality Score (PRISM), the Vasopressor score (VAS) and the Disseminated Intravascular Coagulation score (DIC) [12-14].

\section{Long-term outcome variables Physical health status}

Parents and patients were interviewed by one paediatrician (CB) in a semi-structured format using a standard questionnaire with regard to health consequences since MSS. Complaints were defined as chronic if they developed after MSS and were still present at the time of the visit to the follow-up clinic. The same paediatrician physically examined the patients.

Fifty-eight of the 120 patients (48\%) had skin scarring due to purpura (ranging from barely visible scars to extremely mutilating scars); 10 (8\%) amputation(s) of extremities (ranging from one toe to both legs and one arm); 7 (6\%) lower limb-length discrepancy; 42 (35\%) neurological impairment(s) (mental retardation with epilepsy, hearing loss, chronic headache or focal neurologi- cal signs); and 1(6\%) of the 16 patients with septic shockassociated acute renal failure at PICU admission showed signs of mild chronic renal failure $[1,3]$.

\section{Psychological functioning}

Patients were interviewed and examined by one psychologist (LV) using standard assessment procedures. Intellectual functioning was assessed with two tests for different age ranges: the Wechsler Intelligence Test III (WISC III) for the 6 to 15-year-olds; the Groninger Intelligence Test 2 (GIT2) for the 16 to 31-year-olds [15-17]. Overall, total scores of intellectual functioning were comparable to those of the reference groups [4].

Behavioural and emotional problems were assessed with the Child Behaviour Checklist (CBCL) for the 6 to 18-year-olds, completed by the parents (mothers' reports $\mathrm{n}=75$, fathers' reports $\mathrm{n}=2$ ) and with the Adult SelfReport for the 18 to 31-year-olds patients was used (ASR, $\mathrm{n}=37)[18,19]$. Overall, no significant differences were found between the proportions of patients ( 6 to 18 years and 18 to 31 years separately) scoring in the deviant psychopathological range for problem behaviour and sameaged reference groups (adult patients; unpublished data) [5]. The 90th percentiles of the cumulative frequency distributions of the CBCL and ASR total problem scores obtained for the reference groups served as the cut-offs to distinguish patients scoring in the deviant range from non-problem patients.

Scores in the deviant range reflect levels of problem behaviors similar to those of children, adolescents and young adults typically referred for mental health services. Problem behaviour (a dichotomous variable) was defined as a total problem score above the $90^{\text {th }}$ percentile of the cumulative frequency distribution of the reference groups on a) the CBCL or b) the ASR. Youth Self-Report (YSR) ratings of patients aged 11 to 17 years also served to assess behavioural and emotional problems [18].

\section{$H R-Q o L$}

HR-QoL of patients $<18$ years was assessed with the Child Health Questionnaire (CHQ); that of patients $\geq 18$ years with the Short-Form 36 [20-24]. Significantly poorer scores were found mainly on physical domains. In patients $<18$ years, parents (mothers' reports $\mathrm{n}=60$, fathers' reports $n=20$ ) assigned significantly poorer scores on psychosocial HR-QoL domains, whereas patients $\geq 12$ years self-reported significantly better scores on psychosocial domains [2].

\section{Statistical methods}

Statistical analysis was performed with SPSS 12.0 for Windows (SPSS, Inc, Chicago, IL, USA).

\section{Patient sample}

Comparisons between participating patients and nonparticipants were made with the Mann-Whitney test for 
age at time of PICU admission, length of stay in PICU and severity of illness scores; with the Chi-Square test for sex. Overall physical and psychological outcome

We dichotomised and coded outcome variables (presence or absence of outcome variable), and then generated four major outcome variables; 1$)$ major physical sequelae $(\mathrm{n}=$ 29/120) defined as major scars and/or amputation of extremities and/or limb-length discrepancy; 2) mild neurological impairments $(n=39 / 120)$ defined as hearing loss and/or chronic headache and/or focal neurological signs; 3) problem behaviour ( $\mathrm{n}=16 / 114)$; and 4) total IQ $<85(\mathrm{n}=18 / 115)$. The latter category included three patients with mental retardation and epilepsy whose intelligence score was estimated to be $<70$.

Associations between these major outcomes (all as dichotomous variables) were evaluated with the ChiSquare test.

The psychological outcome variables were also used as continuous variables. In that case the Mann-Whitney test was used to compare these psychological outcome scores between patients with and without major physical sequelae, as well as patients with and without neurological impairments.

\section{Predictors of adverse overall outcome}

Adverse overall outcome was defined as adverse outcome on one or more of the four major outcome variables. The Mann-Whitney test was used to compare age at the time of PICU admission, length of stay in PICU and severity of illness scores between patients with and without adverse overall outcome.

\section{Predictors of HR-QoL}

We tested the association between putative predictor variables (patient's characteristics at the time of PICU admission, long-term physical and psychological outcome variables) and long-term HR-QoL scores by using Spearman correlation for continuous variables and Mann-Whitney test for dichotomous variables. This was only done for those HR-QoL scales for which there were significant differences (poorer or better scores) between the study population and the normative data.

In all of the above mentioned statistical analyses, a $P$ value of 0.05 (two-sided) was considered the limit of significance.

Multiple linear regression analyses were applied to evaluate the predictive value of patient characteristics at the time of PICU admission on long-term HR-QoL scores. This was only done for HR-QoL scales if there were significant differences between the study population and the normative data.

In the regression analysis, we included patient characteristics (age at the time of PICU admission, sex), disease variables (severity of illness scores, length of stay in PICU) and follow-up interval. $P$-values of predictors were set to a level of 0.1 in the univariate analysis for entry in the regression analysis. Using backward elimination, independent predictors were identified with a $P$-value $<$ 0.05 . Continuous predictors with negative regression coefficients were considered as negatively associated with HR-QoL scales, those with positive values as positively associated.

\section{Results}

\section{Patient sample}

The target population consisted of 179 patients. Nine were lost to follow-up: one patient with severe adverse outcome (mental retardation with epilepsy) died several years after the MSS; seven had moved abroad; one was untraceable. Of the remaining 170 eligible patients, 145 agreed to participate. The other 25 patients and/or parents did not respond to the invitation or refused participation on practical or emotional grounds. Eventually, 120 patients visited the follow-up clinic. The median followup interval was 9.8 years (range 3.7 to 17.4 years), the median age of patients at the time of visit to follow-up clinic 14.5 years (range 5.3 to 31.1 years). Twenty-five patients and/or parents did not want to visit the followup clinic on practical (for example, no time because of a busy job) or emotional (too emotional confrontation with the hospital) grounds and preferred to fill in the questionnaires at home. The overall response rate, excluding patients lost to follow-up, was $71 \%(120 / 170)$. To check for possible selection bias, we compared characteristics of participants and non-participants (Table 1). Patients did not differ with respect to age at the time of PICU admission and severity of illness.

At PICU admission a causative organism was isolated in 100 of the 120 patients (83\%) who visited the follow-up clinic. In 99 patients (83\%) Neisseria meningitidis was cultured in blood. Seventy-eight of these (79\%) had NM serogroup B, 13 (13\%) serogroup C and in 8 (8\%) the serogroup was not determined.

\section{Overall physical and psychological outcome}

Seventy-three of the 120 patients (61\%) had adverse outcome on one or more of the four major outcome variables. Forty-seven of these 73 patients had adverse outcome on one major outcome variable: major physical sequelae $n=13$, mild neurological impairments $n=19$, problem behaviour $\mathrm{n}=7$ and total $\mathrm{IQ}<85 \mathrm{n}=8$.

Twenty-six of these 73 patients had adverse outcome on two or three major outcome variables: major physical sequelae and mild neurological impairments $\mathrm{n}=8$, major physical sequelae and problem behaviour $\mathrm{n}=2$, major physical sequelae and total IQ $<85 \mathrm{n}=4$, mild neurological impairments and problem behaviour $\mathrm{n}=4$, mild neurological impairments and total IQ $<85 \mathrm{n}=5$, major physical sequelae, mild neurological impairments and 
Table 1: Data of participating patients and non-participants. Data are presented as number of patients or median (range)

\begin{tabular}{llll}
\hline Characteristics & $\begin{array}{l}\text { Follow-up clinic } \\
\mathbf{n}=\mathbf{1 2 0}\end{array}$ & $\begin{array}{l}\text { No follow-up clinic } \\
\mathbf{n = 5 9}\end{array}$ & $\boldsymbol{P}$-value \\
\hline Sex & 63 boys, 57 girls & 27 boys, 32 girls & $\mathrm{ns}$ \\
Age at admission (years) & $3.1(0.1$ to 17.9$)$ & $5.4(0.2$ to 14.3$)$ & $\mathrm{ns}$ \\
Length of PICU stay (days) & $3(1$ to 51$)$ & $3(1$ to 36$)$ & $\mathrm{ns}$ \\
PRISM & $15(1$ to 37$)$ & $15(0$ to 41$)$ & $\mathrm{ns}$ \\
DIC* & $6(3$ to 8$)$ & $6(2$ to 8$)$ & $\mathrm{ns}$ \\
VAS & $15(0$ to 403$)$ & $11(0$ to 145$)$ & $\mathrm{ns}$ \\
\hline
\end{tabular}

${ }^{*} \mathrm{DIC}$, score $\geq 5$ indicates presence of disseminated intravascular coagulation.

PICU, paediatric intensive care unit; PRISM, Pediatric Risk of Mortality Score; VAS, Vasopressor score; DIC, Disseminated Intravascular Coagulation score.

problem behaviour $\mathrm{n}=2$, mild neurological impairments, problem behaviour and total IQ $<85 \mathrm{n}=1$.

The patient with chronic renal failure had amputation of a leg (below-knee), major scars and focal neurological signs. One of the three patients with mental retardation (estimated IQ < 70) had major scars and amputations; another had major scars and lower limb-discrepancy of 13 centimeters.

There were no significant associations between the presence of the four major outcome variables. No differences were found between patients with major physical sequelae and patients without major physical sequelae as to the presence of problem behaviour or total IQ $<85$. Also, no differences were found between patients with mild neurological impairments and patients without as to the presence of problem behaviour or total IQ $<85$. Finally, no differences were found between patients with major physical sequelae and patients without as to the presence of mild neurological sequelae.

\section{Predictors of overall physical and psychological outcome}

The 73 patients with adverse outcome had significantly longer length of stay in PICU $(P=0.003,4$ versus 2 days $)$ and higher severity of illness scores (PRISM $P=0.001,17$ versus 12) (VAS $P=0.002,25$ versus 6) (all medians) compared with the 47 patients without adverse outcome.

\section{Predictors of HR-QoL}

Univariate analysis of HR-QoL in relation to predictor variables at the time of PICU admission revealed a significant relationship on four HR-QoL scales (Table 2). Age at the time of PICU admission and PRISM showed no significant associations with HR-QoL scores. Multiple linear regression analyses of patient's characteristics at time of PICU admission revealed no significant associations with HR-QoL scores.

Concerning the physical and psychological outcome variables, HR-QoL scores were mainly related with prob- lem behaviour (Tables 3 and 4). There were significant negative associations between all five HR-QoL scales and problem behaviour in the 4-to 17-year-olds (assessed by parents on the $\mathrm{CBCL}$ )) (Table 3). Likewise, there were significant negative associations between HR-QoL scales and problem behaviour in those over 12 years of age (total YSR and total ASR) (Table 4).

\section{Discussion}

From the results of this study we may conclude that major physical sequelae and mild neurological impairments in these survivors of childhood MSS are not associated with problem behaviour or total IQ $<85$. Furthermore, problem behaviour was significantly associated with poorer HR-QoL.

\section{Overall outcome}

To the best of our knowledge, this is the first study investigating associations between different long-term outcome variables in MSS. Erickson et al. described that "some patients had multiple sequelae" [25]. Fellick et al. classified the level of impairment in different categories, based on physical outcome, total intelligence and motor skills [26]. These authors, however, did not evaluate correlations between different outcome variables. In our homogeneous patient sample of MSS survivors those with major physical sequelae after MSS had no more neurological impairments, nor more cognitive dysfunctioning or problem behaviour than those without major physical sequelae. Several explanations present themselves. For one, after a life-threatening illness such as MSS, one may have greater appreciation of life. Indeed, many parents and patients reported that the event had made them stronger and that they tried to make the best of their lives. This phenomenon is referred to as resilience in our previous study [5]. This resilience may be stronger than that in adult patients with critical illness, as sug- 
Table 2: Univariate relations between predictor variables at the time of PICU admission and HR-QoL scales

\begin{tabular}{|c|c|c|c|c|}
\hline Predictor variables & Physical functioning & Self-esteem & Family activities & $\begin{array}{l}\text { Physical summary } \\
\text { ( } \geq 18 \text { years) }\end{array}$ \\
\hline PRISM & - & - & - & - \\
\hline DIC & - & - & $0.48^{* *}$ & $0.39 *$ \\
\hline Length of stay in PICU & $-.31^{* *}$ & - & - & - \\
\hline \multicolumn{5}{|c|}{$P<0.05\left(^{*}\right), P<0.01\left(^{* *}\right),-=$ ns. } \\
\hline \multicolumn{5}{|c|}{ Higher HR-QoL scores indicate more favourable HR-QoL. } \\
\hline \multicolumn{5}{|c|}{$\begin{array}{l}\text { The Spearman correlation coefficient is shown. Plus versus minus sign indicates respectively the positive versus negative association } \\
\text { between the predictor variable and the HR-QoL scale. }\end{array}$} \\
\hline \multicolumn{5}{|c|}{ The scales Physical functioning and Self-esteem are part of the CHQ-PF50 (parent-reports, in patients 4 to 17 years, $n=80$ ). } \\
\hline \multicolumn{5}{|c|}{ The scale Family activities is part of the CHQ-CF87 (patient-reports, in patients 12 to 17 years, $\mathrm{n}=35$ ). } \\
\hline \multicolumn{5}{|c|}{ The scale Physical summary ( $\geq 18$ years) is part of the SF-36 (patient-reports, in patients $\geq 18$ years, $n=38$ ). } \\
\hline
\end{tabular}

gested by Erickson et al. [27]. These authors reported a great deal of "emotionally unresolved grief" (anger, anxiety, depression) in adults who survived invasive meningococcal disease, several years after hospital discharge.

Second, the major physical sequelae were directly related to the severity of MSS [3]. Severity of illness scores, however, were not significant predictors of longterm mild neurological impairments, levels of behavioural problems nor of cognitive dysfunction $[1,4,5]$. It would seem that these latter outcomes were not specifically related to shock and intravascular thrombosis, but rather to acute illness in general. Furthermore, total scores of intellectual functioning and of behavioural and emotional problems in our study group were comparable to those of the reference groups.
We like to add, as is described in details elsewhere, that no association was found between putative predictor variables (age at time of PICU admission, severity of illness scores, presence of meningitis, convulsions and corticosteroids therapy during PICU admission) and longterm mild neurological impairments [1]. As to the association of raised intracranial pressure and long-term mild neurological impairments, measurement of intracranial pressure was not indicated (and was even contraindicated) in our study group, that is, patients with a clinical picture of meningococcal septic shock. Indeed most children had symptoms like altered consciousness and vomiting. However these are nonspecific symptoms of both meningococcal septic shock and elevated intracranial pressure. It could be interesting to test the association between the presence of delirium and adverse neurologi-

Table 3: Univariate relations between physical and psychological outcome variables and HR-QoL parent-reports

\begin{tabular}{lllll}
\hline & $\begin{array}{l}\text { Physical } \\
\text { functioning }\end{array}$ & $\begin{array}{l}\text { General } \\
\text { health perception }\end{array}$ & $\begin{array}{c}\text { Self-esteem } \\
\text { Role functioning } \\
\text { emotional/behavior } \\
\text { summary }\end{array}$ \\
\hline $\begin{array}{l}\text { Major physical sequelae } \\
\text { Mild neurological impairments }\end{array}$ & $-6.3^{*}$ & - & - & - \\
IQ $<85$ & - & - & - & - \\
Total CBCL\# & $-.25^{*}$ & $-.36^{* *}$ & $-.34^{* *}$ & $-28.9^{* *}$
\end{tabular}

For dichotomous variables (first three items) the difference (item present minus absent) in mean HR-QoL scale value is shown, for continuous variables (last item) the Spearman correlation coefficient is shown. Plus versus minus sign indicates respectively the positive versus negative association between the predictor variable and the HR-QoL scale.

$P<0.05\left(^{*}\right), P<0.01\left(^{* *}\right),-=$ ns.

\#CBCL (Child Behavior Checklist) is the parent-report of behavioural and emotional problems in patients $<18$ years. Higher CBCL scores indicate unfavourable outcome.

The HR-QoL scales are part of the CHQ-PF50 (parent-reports, in patients 4 to 17 years, $n=80$ ).

HR-QoL scales range from 0 to 100 . Higher HR-QoL scores indicate more favourable HR-QoL. 
Table 4: Univariate relations between physical and psychological outcome variables and HR-QoL patient-reports

\begin{tabular}{|c|c|c|c|c|c|c|}
\hline $\begin{array}{l}\text { Predictor } \\
\text { variables }\end{array}$ & $\begin{array}{c}\text { Family } \\
\text { activities }\end{array}$ & $\begin{array}{c}\text { General } \\
\text { health } \\
\text { perception }\end{array}$ & $\begin{array}{c}\text { General } \\
\text { behaviour }\end{array}$ & $\begin{array}{c}\text { Role } \\
\text { limitations } \\
\text { emotional }\end{array}$ & Vitality & $\begin{array}{l}\text { Psychosocial } \\
\text { summary }\end{array}$ \\
\hline $\begin{array}{l}\text { Major physical } \\
\text { sequelae }\end{array}$ & $6.2^{*}$ & - & - & - & - & - \\
\hline $\begin{array}{l}\text { Mild neurological } \\
\text { impairments }\end{array}$ & $-12.3^{*}$ & - & - & $-10.1^{*}$ & $-11.6^{*}$ & \\
\hline Total YSR\# & $-.52^{* *}$ & $-.34^{*}$ & $-.60^{* *}$ & - & - & - \\
\hline Total ASR\#\# & - & - & - & $-.53^{* *}$ & $-.44^{* *}$ & $-.56^{* *}$ \\
\hline \multicolumn{7}{|c|}{$\begin{array}{l}\text { For dichotomous variables (first two items) the difference (item present minus absent) in mean HR-QoL scale value is shown, for continuous } \\
\text { variables (last two items) the Spearman correlation coefficient is shown. Plus versus minus sign indicates respectively the positive versus } \\
\text { negative association between the predictor variable and the HR-QoL scale. } \\
P<0.05\left({ }^{*}\right), P<0.01\left({ }^{* *}\right),-=\text { ns. } \\
\text { \#YSR (Youth Self-report) and ASR \#\# (Adult Self-Report) are self-reports of behavioural and emotional problems in resp. patients } 11 \text { to } 17 \text { years } \\
\text { and }>18 \text { years. Higher YSR and ASR scores indicate unfavourable outcome. } \\
\text { The scales Family activities, General health perception, General behaviour are part of the CHQ-CF87 (patient-reports, in patients } 12 \text { to } 17 \text { years, } \\
\mathrm{n}=35 \text { ). } \\
\text { The scales Role limitations due to emotional problems, Vitality, Psychosocial summary are part of the SF-36 (patient-reports, in patients } \geq 18 \\
\text { years, } \mathrm{n}=38 \text { ). } \\
\text { HR-QoL scales range from } 0 \text { to } 100 \text {. Higher HR-QoL scores indicate more favourable HR-QoL. }\end{array}$} \\
\hline
\end{tabular}

cal outcome. Unfortunately, the presence of delirium after PICU admission was not investigated.

So in our study group it seems that adverse long-term physical and psychological outcomes in survivors of MSS were not related. However, some specific cases should be mentioned, but they were insufficient to result in statistically significant differences: for example, two of the three patients with mental retardation (estimated IQ < 70) had major physical sequelae; the patient with chronic renal failure had major physical sequelae and focal neurological signs.

\section{Predictors of HR-QoL}

Long-term poorer HR-QoL was mainly predicted by less favourable scores on behavioural and emotional problem scales. HR-QoL scores, both on the physical and psychosocial domains, were significantly associated with problem behavior (total CBCL, total YSR, total ASR), regardless of age and parent-report versus patient-report. These findings are in line with those from a study by Koomen et al. in children 4 to 10 years after bacterial meningitis [28]. This comparison requires caution, however, because MSS is a more severe disease (for example, multiple organ failure) than bacterial meningitis.

HR-QoL scores were to a lesser amount significantly associated with adverse physical outcome; patients with major physical sequelae had significantly poorer scores on the HR-QoL scale physical functioning. Indeed, amputation or limb-length discrepancy often resulted in important long-term morbidity (pain, functional impairment) in our study group [3]. Surprisingly the HR-QoL scale general health perception was not significantly associated with the presence of major physical sequelae or mild neurological impairments. The significantly poorer scores on this HR-QoL scale, therefore, most likely reflected future health status, rather than the present one.

Studies regarding long-term HR-QoL in survivors of other severe illnesses, for example, congenital heart diseases, also demonstrated weak associations between present physical health status and HR-QoL $[29,30]$.

Seeing that DIC and VAS, but not PRISM, showed small to moderate correlations $\left(\mathrm{r}_{\mathrm{s}}<0.7\right)$ on a minority of HR-QoL scales only in univariate analysis, the severity of MSS in childhood, regardless of any adverse outcome, seemed less important for long-term HR-QoL.

\section{Limitations of the present study}

Several limitations of our study should be acknowledged. This is an observational study (without a suitable control group) in one centre. The response rate was not high (71\%), but we believe the results are valid since participating patients and non-participants did not differ with respect to age at time of PICU admission and severity of illness. It should be emphasized that only the most critically ill patients, that is, MSS patients requiring intensive treatment, were included. Therefore our findings cannot be extrapolated to the milder cases (sepsis) admitted to a general ward. Finally, baseline assessments of health status, psychological functioning and HR-QoL (before MSS) were not available, which would obviously be difficult to measure reliably under such stressful circumstances. 


\section{Conclusions}

Long-term adverse physical and psychological outcome variables were independently distributed, not clustered together. For example, patients suffering from severe skin scarring or extensive amputation did not show more problem behaviour and cognitive dysfunctioning compared with patients without severe skin scarring or extensive amputation. Poorer HR-QoL was mainly predicted by problem behaviour.

More conclusive evidence could be obtained from a study comparing MSS survivors with survivors of other critical illness, matched on age and follow-up interval.

\section{Key messages}

- Seventy-three of the 120 patients (61\%) had adverse outcome on one or more of the physical and psychological outcome variables.

- The 73 patients with adverse outcomes had significantly longer length stays in PICU and higher severity of illness scores compared with the 47 patients without adverse outcomes.

- Patients suffering from severe skin scarring or extensive amputation did not show more problem behaviour and cognitive dysfunction compared with patients without severe skin scarring or extensive amputation.

- Patient's characteristics at the time of PICU admission revealed no significant associations with HRQoL scores.

- Concerning the physical and psychological outcome variables, HR-QoL scores were mainly related with problem behaviour.

\section{Abbreviations}

ASR: Adult Self-Report; DIC, CBCL: Child Behaviour Checklist; CHQ: Child Health Questionnaire; Disseminated Intravascular Coagulation score; HR-QoL: healthrelated quality of life; MSS: meningococcal septic shock; NM: Neisseria meningitidis; PICU: paediatric intensive care unit; PRISM: Pediatric Risk of Mortality Score; VAS: vasopressor score; YSR: Youth Self-Report.

\section{Competing interests}

The authors declare that they have no competing interests.

\section{Authors' contributions}

CMPB initiated this study and created the database, performed the statistical analysis and wrote the manuscript. LCACV assisted in creating the database, the interpretation of the results and writing of the manuscript. HR assisted in interpretation of the results and critically read the manuscript; JAH critically read the manuscript and assisted in interpretation of the results. WCJH performed the statistical analysis and assisted in the interpretation of the results and writing of the manuscript. EMWJ assisted in the interpretation of the results and writing of the manuscript. KFMJ initiated this study and assisted in the interpretation of the results and writing of the manuscript.

\section{Acknowledgements}

This study was financially supported by a grant from the Hersenstichting Nederland (Dutch Brain Foundation), grant number: 14F06.03. We thank our in-

house editor, Ko Hagoort, for reviewing this article.

\section{Author Details}

1 Department of Paediatrics, Division of Paediatric Intensive Care, Erasmus MC Sophia Children's Hospital, Dr. Molewaterplein 60, Rotterdam, 3015 GJ, The Netherlands, 2Department of Child and Adolescent Psychiatry, Erasmus MCSophia Children's Hospital, Dr. Molewaterplein 60, Rotterdam, 3015 GJ, The Netherlands, ${ }^{3}$ Department of Public Health, Erasmus MC, Dr. Molewaterplein 60, Rotterdam, 3015 GJ, The Netherlands and 4 Department of Epidemiology and Biostatistics, Erasmus MC, Dr. Molewaterplein 60, Rotterdam, 3015 GJ, The Netherlands

Received: 8 January 2010 Revised: 1 April 2010

Accepted: 29 June 2010 Published: 29 June 2010

\section{References}

1. Buysse CM, Raat H, Hazelzet JA, Hulst JM, Cransberg K, Hop WC, Vermunt LC, Utens EM, Maliepaard M, Joosten KF: Long-term health status in childhood survivors of meningococcal septic shock. Arch Pediatr Adolesc Med 2008, 162:1036-1041.

2. Buysse CM, Raat H, Hazelzet JA, Vermunt LC, Utens EM, Hop WC, Joosten $\mathrm{KF}$ : Long-term health-related quality of life in survivors of meningococcal septic shock in childhood and their parents. Qual Life Res 2007, 16:1567-1576.

3. Buysse CM, Oranje AP, Zuidema E, Hazelzet JA, Hop WC, Diepstraten AF, Joosten KF: Long-term skin scarring and orthopaedic sequelae in survivors of meningococcal septic shock. Arch Dis Child 2009, 94:381-386.

4. Vermunt LC, Buysse CM, Aarsen FK, Catsman-Berrevoets CE, Duivenvoorden HJ, Joosten KF, Hazelzet JA, Verhulst FC, Utens EM: Longterm cognitive functioning in children and adolescents who survived septic shock caused by Neisseria meningitidis. Br J Clin Psychol 2009, 48:195-208.

5. Vermunt LC, Buysse CM, Joosten KF, Hazelzet JA, Verhulst FC, Utens EM: Behavioural, emotional, and post-traumatic stress problems in children and adolescents, long term after septic shock caused by Neisseria meningitidis. Br J Clin Psychol 2008, 47:251-263.

6. Abraham E, Matthay MA, Dinarello CA, Vincent JL, Cohen J, Opal SM, Glauser M, Parsons P, Fisher CJ Jr, Repine JE: Consensus conference definitions for sepsis, septic shock, acute lung injury, and acute respiratory distress syndrome: time for a reevaluation. Crit Care Med $2000,28: 232-235$

7. Joosten KF, de Kleijn ED, Westerterp M, de Hoog M, Eijck FC, Hop WCJ, Voort EV, Hazelzet JA, Hokken-Koelega AC: Endocrine and metabolic responses in children with meningoccocal sepsis: striking differences between survivors and nonsurvivors. J Clin Endocrinol Metab 2000, 85:3746-3753.

8. de Kleijn ED, de Groot R, Hack CE, Mulder PG, Engl W, Moritz B, Joosten KF, Hazelzet JA: Activation of protein $C$ following infusion of protein $C$ concentrate in children with severe meningococcal sepsis and purpura fulminans: a randomized, double-blinded, placebo-controlled, dosefinding study. Crit Care Med 2003, 31:1839-1847.

9. Derkx B, Wittes J, McCloskey R: Randomized, placebo-controlled trial of HA-1A, a human monoclonal antibody to endotoxin, in children with meningococcal septic shock. European Pediatric Meningococcal Septic Shock Trial Study Group. Clin Infect Dis 1999, 28:770-777.

10. de Groof F, Joosten KF, Janssen JA, de Kleijn ED, Hazelzet JA, Hop WC, Uitterlinden P, van Doorn J, Hokken-Koelega AC: Acute stress response in children with meningococcal sepsis: important differences in the growth hormone/insulin-like growth factor I axis between nonsurvivors and survivors. J Clin Endocrinol Metab 2002, 87:3118-3124.

11. Vermont $C L$, den Brinker $M$, Kakeci $N$, de Kleijn $E D$, de Rijke $Y B$, Joosten KF, de Groot R, Hazelzet JA: Serum lipids and disease severity in children with severe meningococcal sepsis. Crit Care Med 2005, 33:1610-1615.

12. Pollack MM, Ruttimann UE, Getson PR: Pediatric risk of mortality (PRISM) score. Crit Care Med 1988, 16:1110-1116.

13. Wernovsky G, Wypij D, Jonas RA, Mayer JE Jr, Hanley FL, Hickey PR, Walsh AZ, Chang AC, Castaneda AR, Newburger JW, et al:: Postoperative course and hemodynamic profile after the arterial switch operation in neonates and infants. A comparison of low-flow cardiopulmonary bypass and circulatory arrest. Circulation 1995, 92:2226-2235. 
14. Taylor FB Jr, Toh CH, Hoots WK, Wada H, Levi M: Towards definition, clinical and laboratory criteria, and a scoring system for disseminated intravascular coagulation. Thromb Haemost 2001, 86:1327-1330.

15. Kort W, Schittekatte M, Compaan EL, Bosmans M, Bleichrodt N, Vermeir G, Resing WCM, Verhaeghe P: WISC-III NL Handleiding Nederlandse bewerking London: The Psychological Corporation; 2002.

16. Wechsler D: Manual for the Wechsler Intelligence Scale for Children 3rd edition. San Antonio, TX: The Psychological Corporation; 1991.

17. Luteijn F, Barelds DPH: Groninger Intelligence Test 2 (GIT2) Amsterdam: Harcourt; 2004.

18. Achenbach TM, Rescorla LA: Manual For The ASEBA School-Age Forms \& Profiles Burlington, VT: University of Vermont, Research Center for Children, Youth \& Families; 2001.

19. Achenbach TM, Rescorla LA: Manual For The ASEBA Adult Forms \& Profiles Burlington, VT: University of Vermont, Research Center for Children, Youth, \& Families; 2003.

20. Ware JE Jr, Sherbourne CD: The MOS 36-item short-form health survey (SF-36). I. Conceptual framework and item selection. Med Care 1992, 30:473-483

21. Raat H, Bonsel GJ, Essink-Bot ML, Landgraf JM, Gemke RJ: Reliability and validity of comprehensive health status measures in children: The Child Health Questionnaire in relation to the Health Utilities Index. J Clin Epidemiol 2002, 55:67-76.

22. Raat H, Landgraf JM, Oostenbrink R, Moll HA, Essink-Bot ML: Reliability and validity of the Infant and Toddler Quality of Life Questionnaire (ITQOL) in a general population and respiratory disease sample. Qual Life Res 2007, 16:445-460.

23. Raat H, Landgraf JM, Bonsel GJ, Gemke RJ, Essink-Bot ML: Reliability and validity of the child health questionnaire-child form (CHQ-CF87) in a Dutch adolescent population. Qual Life Res 2002, 11:575-581.

24. Aaronson NK, Muller M, Cohen PD, Essink-Bot ML, Fekkes M, Sanderman R, Sprangers MA, te Velde A, Verrips E: Translation, validation, and norming of the Dutch language version of the SF-36 Health Survey in community and chronic disease populations. J Clin Epidemiol 1998, 51:1055-1068.

25. Erickson L, De Wals P: Complications and sequelae of meningococcal disease in Quebec, Canada, 1990-1994. Clin Infect Dis 1998, 26:1159-1164.

26. Fellick JM, Sills JA, Marzouk O, Hart CA, Cooke RW, Thomson AP: Neurodevelopmental outcome in meningococcal disease: a casecontrol study. Arch Dis Child 2001, 85:6-11.

27. Erickson LJ, De Wals P, McMahon J, Heim S: Complications of meningococcal disease in college students. Clin Infect Dis 2001, 33:737-739.

28. Koomen I, Raat H, Jennekens-Schinkel A, Grobbee DE, Roord JJ, van Furth $\mathrm{M}$ : Academic and behavioral limitations and health-related quality of life in school-age survivors of bacterial meningitis. Qual Life Res 2005, 14:1563-1572

29. Kamphuis M, Ottenkamp J, Vliegen HW, Vogels T, Zwinderman KH Kamphuis RP, Verloove-Vanhorick SP: Health related quality of life and health status in adult survivors with previously operated complex congenital heart disease. Heart 2002, 87:356-362.

30. Spijkerboer AW, Utens EM, De Koning WB, Bogers AJ, Helbing WA Verhulst FC: Health-related Quality of Life in children and adolescents after invasive treatment for congenital heart disease. Qual Life Res 2006, $15: 663-673$

doi: $10.1186 /$ cc9087

Cite this article as: Buysse et al., Surviving meningococcal septic shock in childhood: long-term overall outcome and the effect on health-related quality of life Critical Care 2010, 14:R124

\section{Submit your next manuscript to BioMed Central} and take full advantage of:

- Convenient online submission

- Thorough peer review

- No space constraints or color figure charges

- Immediate publication on acceptance

- Inclusion in PubMed, CAS, Scopus and Google Scholar

- Research which is freely available for redistribution

Submit your manuscript at www.biomedcentral.com/submit
C Biomed Central 